\title{
SECA, FERROVIAS E MÃO DE OBRA (SÉCULO XIX)
}

\section{Josemir Camilo de Melo*}

Este artigo pretende analisar o comportamento do Estado imperial e das empresas capitalistas, inglesas e nacionais frente ao surto da grande seca de 1877 a 1879 , no tocante ao transporte da produção agrícola e de pessoas, no intuito de observar o grau de calamidade e vulnerabilidade a que a região esteve exposta durante aquele flagelo. Foram tomadas as Províncias de Pernambuco e Paraíba como ponto central, onde se procedeu a pesquisa com mais afinco. $\mathrm{O}$ que queremos verificar neste artigo é de como as ferrovias serviram durante a seca, não só quanto ao transporte de gêneros de primeira necessidade e de flagelados, mas como teria se beneficiado da mão de obra barata dos migrantes e como foi usada no combate direto à calamidade.

As ferrovias foram constirúdas tendo em mira o transporte de mercadorias, numa ótica neocolonialista, cujo traçado ia da área produtiva diretamente para o porto. 0 transporte de passageiros fazia parte da pauta, mas não cra o essencial em termos de receita, visto que o país era extremamente pobre e, mais do que isto, existia o trabalho escravo, o que impedia esta camada de trabalhadores de ser usuário daquele meio de transporte.

As ferrovias começaram a ser construídas no Brasil, a partir da lei ferroviária de 1852. A primeira foi a curta estrada privada do banqueiro Irineu Evangelista de Souza (Barão e Visconde de Mauá) em 1854. Depois foi a vez dos ingleses no Nordeste, com a Recife-São Francisco, em 1858. Daí por diante, houve um surto de construçōes ferroviárias, de iniciativa privada, cujo descenso ocorreu durante a guerra com o Paraguai, sendo um segundo ciclo de construções iniciado em $1873 \mathrm{com}$ um novo regimento ferroviário.

"Doutorando em História - UFPE; Professor do Departamento de História e Mestrado em Sociologia da UFPB; Coordenador da Pesquisa "Históna das Secas no Nordeste: Cronologia e Impactos". CNPq/PIBIC. 


\section{SECAS nO NORDEStE nO SÉCULO XIX}

A seca, no século XIX, torna-se cada vez mais uma calami-. dade, apesar de politicamente o Brasil ter evoluido, saindo do estatuto colonialista para o de nação. Isto se verifica por duas vertentes: una, que é maior o número de pessoas atingidas pelo flagelo da seca, devido ao próprio crescimento vegetativo da população; outra, que sendo uma nação, os aparelhos burocráticos e ideológicos do Estado tomarão a si o registro das calamidades, muito embora isto não seja acompanhado de soluções políticoadministrativas.

Assim é que mal começamos o século XIX e já nos deparamos com a seca de $1803 / 4$, principalmente registrada na Paraíba. Destruiu pastos e elevou o preço da farinha, causou mortes de fome e uma onda de roubos. O governo pediu ajuda de víveres a Bahia. A exportação de algodão caiu em Pernambuco naqueles dois anos em 25\% e 18\%. Ainda naquela década, em 1809, houve seca e a exportação de algodão em Pernambuco caiu no ano seguinte em 8\%. Parece um ciclo de 6 a 7 anos, pois surge seca em $1816 / 7$, embora parcial, de pouca duração. Talvez um dos paliativos do Reino Unido, à época tenha sido o de enviar plantas frutíferas exóticas, como canela, cravo e pimenta da Índia, fruta-pão e café, que em boa parte registiram a seca de $1824^{(64)}$.

Em 1824/5, quando a região que e hoje o Nordeste estava sacuolida pela revolta denominada de Confederação do Equador, ocorreu outra seca. Houve falta de farinha, enquanto que os agricultores estavam em armas, de um ou outro lado e que 1/3 da população da seca teria morrido junto com a guerra civil. Em 1825, na Paraíba, falta chuva até nos brejos; fazem farinha de xiquexique no sertão do Curimataú. Os monges beneditinos perdem 30 escravos por morte. No Ceará, segundo Gardner, teria morrido cerca de 30.000 pessoas ${ }^{65}$.

\footnotetext{
64 ALMEDDA, José Américo de. A Paraiba o Seus Problemas, p. 173; CUNHA, Eudides da. A Margem da História, passim; PEREIRA DA COSTA, F.A. Anais Pernambucanos, Vol.VII, p.39.
}

65 GARDNER, George, p.157, edica inglesa "Travels in the Interior of Brazil, principally throug fhe Norhern Provinces and tho Gold and Diamond Districts during the years 1836 - 
Em 1826/7 aparecem secas parciais. Na Paraíba, concluiu-se o açude velho em Campina Grande. Em 1830, há falta de chuvas e o Presidente da Província pede ajuda para comprar farinha. A seca volta em 1835/7. Em 1844/6 a seca ataca Paraíba e Pernambuco, causando emigração. O Ministério do Império envia 1.322 alqueires de farinha para Areia, zona de brejo (Pb). Em Sousa, morrem cerca de 20 pessoas por dia (1846). Durante a seca de 1846, as autoridades providenciaram 136.000 sacas de gêneros alimentícios. $O$ presidente solicitou 130 sacos de farinha e remeteu para Piancó e Sousa 400 mil réis; para Pombal, 200 mil réis para comprar farinha. Miséria em Campina Grande e em Ingá. Comprou-se em Pernambuco mil sacas de farinha a 4 contos 622 mil e 500 réis, pagos pelo comerciante e coronel da Guarda Nacional Francisco Alves de Souza, pelo Tesouro da Província para ser reembolsado. O Presidente solicitou ainda 1.000 reses para o sertão, para recriar os rebanhos destruídos pela seca. Em 1845, em Piancó, o alqueire de farinha chegou a $60 \mathrm{mil}$ réis, quando normalmente era vendido por 3 e 4 mil réis. Os agiotas tiraram proveito da situação. O Ministério do Império (não havia sido criado o da Agricultura) enviou 135.272 sacas de farinha ${ }^{66}$.

Afora estas secas, há que contar com os invernos falhos, os chamados repiquetes como os dos anos 1851 e 53, 1860, 1865/66, bem como de 1867 a 1870; alguns repiquetes surgem em 1870/72, no sertäo de Alagoas e Pernambuco, até estourar na seca de 1877. Depois da seca de 1888 , há o repiquetes de $1889,1891 / 2$, a seca de 1895 e repiquete em $1896^{\left(6^{7}\right)}$.

1841". New York, AMS Press, 1970; Almeida, op. cit. p.174; REBOUÇAS, Audré. A Seca na s Provincias do Norto. Socorros Públicos. p. 29, PEREIRA DA COSTA, F.A. Anais Pomambucanos, Vol VI, p.236.

66 ALMELD, op, cit. p.175; PIN'TO, Irineu Ferreira. Datas e Notas para a Históna da Paraíba, p. 170; CUNHA, op. cit, passim; Antôtio Pedro de Figueiredo confima a existência de seca, sem dar majores detalhes, em O Progiesso, p. 313. 


\section{A SECA DE 1877, PANORAMA REGIONAL}

Na seca de 1877, a capital da Paraiba recebera cerca de 35.000 flagelados. A solução encontrada, então, foi de fundar colônias de flagelados, tendo que alojar 12.000 deles em colônias, espalhadas na área canavieira. Se a projetada ferrovia Conde D'Eu já estivesse operando, os sertanejos poderiam ter sido beneficiados, como foram na seca de 1890 , quando aquela companhia transportou 4.000 sacas de farinha, milho e feijão para as zonas limítrofes da seca ${ }^{68}$.

O combate à calamidade ficou a cargo do governo imperial, que abriu crédito de 5 contos de réis para alimentos. Pilhagens, assaltos, grupos de cangaceiros. Jesuino Brilhante que despontou no cangaço durante esta seca, em Campina Grande, estendeu suas açôes para o oeste do Rio Grande do Norte. Havia na região cinco grupos de bandidos. No brejo a lavoura é destruída pelo criado solto, o que diminui a oferta de alimentos. 400 flagelados entram em Mamanguape. $O$ governo pöe os flagelados para trabalhar em obras públicas: açudes, cadeias, estradas. Abriu mais três créditos de 12 contos de réis. Os estudantes da Politécnica arrecadaram 2 contos, 421 mil réis. O Pará enviou 4 contos e 300 mil réis. O Espírito Santo e o Paraná também enviaram ajudas ${ }^{69}$.

Flagelados foram empregados no acude de Arara. O governo envia 2 contos de réis para construir a cadeia de Campina e 1 conto para o açude de Princesa. Grupo de ladrões armados invadem Cajazeiras e roubam 4 conlos (1878). Começa a emigração para Mossoró e Ceará e 35 mil retirantes invadem a capital da Paraíba. O governo adota a emigração para fora da província, por navios e criam-se colônias agrícolas. Os mortos, na capital, entre maio e setembro atingem $7.073^{(70)}$. Em 1879 , em cinco meses, o número de mortos atinge 1.596 na capital $^{71}$.

69 Lúcia de Frátima Guerra dá 8.920 flagelados vivendo nas Colônias de Socorro. FERREIRA, Lúcia de Fásima Guerra. A Seca de 1877 na Parába. In: Rev. de Ciências Humanas, p.203

69 ALMEIDA, op. cit. p.
70 ALMEIDA, op. Cit. p.
7 ALMEDA, op. cit. pp.205/6. 
A sociedade começa a fazer crítica da aplicação de verbas em cadeias, cemitérios e igrejas e câmaras municipais. As obras de açudagem na Paraíba estavam alocadas em Teixeira, Mogeiro (Itabaiana) Espírito Santo (Cruz do), Santa Luzia (iniciada pelo Padre Ibiapina) Guarabira. Em uso estavam o de Belém do Arrojado, construído pelo padre Ibiapina e o de Princesa. O padre Rolim tinha um açude particular e o franqueou à população ${ }^{72}$.

A seca de 1877 , no Rio Grande do Norte, causou um grande colapso na economia local. o Governo provincial havia dado uma concessão para construir uma ferrovia, que não pode ser iniciada naquela década. Mossoró teve $78 \%$ de sua população junto com emigrados, atingidos pela seca, com mortes e escassez de tratamento de doentes e de gêneros. Cerca de 117.000 habitan. tes da província precisava de socorros. Em todo o Nordeste, o povo atingido por aquela seca, chegou à cerca de 2.147.000 habitantes. Rio Grande do Norte ocupava o terceiro lugar em número de vítimas, chegando a perder 80.000 habitantes; o governo imperial criou dois depósitos de alimentos, um em Natal e outro em Mossoró. Ainda em 1882 era grande o número de flagelados na capital, a ponto de o Presidente da Província mandar reforçar o policiamen$\mathrm{to}^{73}$.

Mossoró, que antes chegara a ter 25.000 habitantes flutuantes por causa da seca, passando fome e morrendo de miséria ou de peste, a tudo se expondo para receber um litro de farinha; o número quase que dobrou passando para 45.000 flagelados, número este que chegou a 70.000, morrendo 35.000 deles, entre 1878 e

\footnotetext{
72

O Padre Ibiapina, desde 1862, juntava à sua pregação missionária, o trabalho de abrir cacimbas (Barbalha, CE), açudes (Angicos, RN, Arara e Soledade, PB e em Caldas, CE), ainda na década do 1860 MARIZ, Celso. Ibiapina, um Apóstolo do Nordeste, pp.65, 73, 75; PINHEIRO, Francisco José. O Homem Livre/Pobre a a Organização das Relações de Trabalho no Cearáa (1850-1880), pp.227/230.

${ }^{73}$ REBOUÇAS, op. oit. pp.33/4; CÂMARA CASCUDO, Luís da. História do Rio Grande do Norte, pp. 181/2; SПVA, Allpio Pereira da, Consideraçōes Gerais sobre as Provincias do Ceará e Rio Grande do Norte, p.4; TAKEYA, Denise. Un Outro Nordeste: O Algodão na Economia do Rio grande do Norte (1880-1915), p.92; em 1884, houve seca e epidemia de variola que atingiu cerca de 40.000 pessoas, muitos morreram e outros emigraram, $\theta$ o governo teve que gastar o equivalente a 600.000 libras para socorrer a população. Ver The Rai-lway Times, April 26, 1884, pp.534/5 o May 2, 18885, pp.551/2
} 
1879. Outra fonte calculou que esta província teria perdido mais de 80.000 habitantes, entre $187731879^{(74)}$.

A seca de 1877/9 no Ceará, começou ainda em junho de 1876 foi a mais virulenta do século. Rebouças diz que em Fortaleza em outubro de 1877 havia mais de 17.000 retirantes (p.57). Castro Carreira, um dos incentivadores da EF Baturité, diz que o Ceará perdeu cerca de 400 mil pessoas, sendo que só $200 \mathrm{mil}$ foram vitimadas pela peste. Diplomatas ingleses calculavam que cerca de 300 mil pessoas tinham morrido e cerca de 250 mil teria emigrado ${ }^{75}$.

Só para se ter uma idéia da calamidade, agentes diplomáticos ingleses levantaram dados sobre a precipitação pluviométrica do Ceará. A década de 1870 foi terrivel para o Ceará. Em 1873, teria caído somente $853 \mathrm{ml}$; depois viria o ano de 1874 com $855 \mathrm{ml}$. Em 1877, choveu apenas $355 \mathrm{ml}$, aumentado no ano seguinte para $517 \mathrm{ml}$ e em 1879 chegando ainda a 621 . Somente em 1867, o Ceará tinha tido chuvas abaixo de 1000 mililitros $^{76}$.

Já no início de 1878 , a seca mostrava queda na exportação cearense do algodão, que de 55.510 sacos em 1873 , tinha passado a 34.853 sacos, enquanto açúcar e café, produtos serranos tiveram sua produção aumentada, já que a região do Cariri cearense fora incorporada ao mercado a partir da década de $1850^{(7)}$. Também aumentou a exportação cearense de escravos naqueles anos de seca, de 768 (em 1876) para $1.725,2.909$ e 1.925 nos três anos de 1877a 79, respectivamente. E sintomático que a Sociedade funda-

${ }^{74}$ CAMMARA CASCUDO, Luis da. op.cit, pp. 184/5; SILVA, Clodomiro Pereira da. Política e Legislação de Estradas de Ferro, p.4; GUERRA. Phelippe e GUERRA, Theópbilo. Seccas contra Secca, p.38.

${ }^{73}$ BPP LXXXIX, 1881. Report by Consul Bonham of the Provinces of Alagoas, Paraiba, Rio Grande do Norte e Ceará, 1879, p.24; FERREIRA, Benedito Genésio, A Estrada de Ferro do Baturité: 1870-1930, pp. 51,2; CASTRO CARREIRA, Liberato de. História Financeira o Orçamentária do Império no Brasil, p.540; CONRAD, Robert. Os Úl-timos Anos da Escravatura no Brasil, p.215, MELO, Josemir Camilo de. Ceará: Abolição Precoce ou Crise Econômica?, pp. 35/36.

${ }^{76}$ BPP LXXXTX, 1881. Report by Consu' Bonham, op. cit. p. 24 .

${ }^{77}$ The Brazilian and River Plate Mail. March 8, 1878, p.2; PINHEIRO, op. cit. p. 200. 
da para emancipar escravos tenha surgido exatamente em $1879^{(78)}$.

Alagoas, por sua vez, tendo apenas uma pequena parte encravada na área da seca, recebeu flagelados do sertão pernambucano. A metade da população de Palmeira dos. Indios abandonou as plantações e se passou para a zona canavieira. Em maio de 1878, já havia 30.000 retirantes na Província, vindos do sertāo do São Francisco, de Pernambuco e da Paraíba. Recife, por sua vez já havia recebido 1.424 retirantes cearenses que vieram de navio, além de 4.023 retirantes que vieram do próprio sertão pernambucano. Em 1879, Recife diminuiria sua populacão de 60.000 flagelados para $2.000^{(79)}$.

\section{A POLÍTICA DE CONSTRUÇÃO DE ESTRADAS}

$\mathrm{Na}$ seca de 1846 não foi possivel atender com presteza as populaçōes do sertão, porque simplesmente nāo havia estradas. No relatório do Presidente da Paraíba, Carneiro de Campos, se vê que "(..) não foi possível remeter a farinha para o sertão". $O$ governo enviou 400 mil réis em espécie (cerca de 220 dólares) para Piancó e Souza e 200 mil-réis (110 dólares) para Pombal. Tornouse praxe enviar dinheiro para comprar mantimento no local. $O$ problema é que a seca já teria destruído as lavouras. Se os gêneros não podiam ser levados para o sertão por falla de estradas, os retirantes usavam as trilhas e caminhos, no sentido inverso para a zona da mata e litoral. Para se ver como a falta de rodagem impedia o envio de mantimentos, naquela seca, o governo mandou 130 sacas de farinha para o sertão, no mês de fevereiro. Em março ele resolveu visitar Campina Grande e adjacências e encontrou as mesmas sacas ainda naquela cidade. Como os flagelados eram

${ }^{78}$ Consul Bonham, Idem, p.25; CONRAD, Robert. Op. cit p.213.

${ }^{79}$ SANTANA, Moacir Medeiros de. Contribuições à História do Açúcar em Alagoas, pp. 171 a 174; (Melo) CAMLO (de). Josenir. A Seca de 1877 a a Mão de Obra na Zona da Mata om Pemambuco. pp.45 e 47; Relatónos de Presidentes de Provincia, 1879 ; Gazeta de Notícias. Rio de Janeiro, 16 de jumb de 1878 apud CAMחO, op. cit. 
muitos, mandou distribuir ali mesmo ${ }^{80}$.

O Presidente da Paraíba, por volta de 1858, o engenheiro militar Henrique de Beaurepaire Rohan, mandou abrir uma rodovia até a cidade de Areia, oferecendo $5 \%$ de juros à companhia que se organizasse para aquele fim. Tudo que a Província tinha à época eram 30 léguas $(180 \mathrm{~km})$ de trilhos, atalhos, caminhos e nâo estradas propriamente ditas ${ }^{81}$. Em 1864, o Presidente da Paraíba contrata o engenheiro André Reboucas para fazer o levantamento topográfico para uma rodagem que partisse da cidade de Areia, no brejo paraibano, para a capital da Província, às margens do rio Sanhauá, perto do litoral.

Em Pernambuco, estradas começaram a ser feita por volta de 1802 , mas não passavam do perímetro de Recife, algo em torno de $32 \mathrm{~km}$. Anteriormente, por volta de 1774, fora tentado um trecho que não chegaria a $20 \mathrm{~km}$ e de apenas 15 palmos de largura. Por isto, o algodão vinha de 100 a 150 léguas em lombos de animais, viagem que levava até seis semanas. $\mathrm{Em} 1866$, a província já teria cerca de $236 \mathrm{~km}$ de rodagens precárias, estreitas, verdadeiros caminhos de comboios de tropeiros ${ }^{82}$.

\section{FERROVIAS}

Algumas ferrovias no Nordeste foram construídas, ou encampadas pelo governo, como resultado da grande seca de 1877 . Pelo, menos 3 delas tiveram iniciativa da Província ou do Estado Imperial como socorro àquela tragédia. Duas no Ceará, a EF Baturité e a EF Sobral; a EF Paulo Afonso, construída entre Alagoas e Pernambuco. Com respeito a esta úlima, havia o receio de que, tendo o governo Imperial iniciado a ferrovia de Paulo Afonso, entre Piranhas e Jatobá, os retirantes abandonassem a Colônia de São Francisco, em busca de trabalho remunerado na estrada de

80

PINTQ op. cit. p. 175 .

81 Idem, p.261.

82 PERERA DA COSTA, F.A. Anais Pemambucanos, 1795-1817. Vol.VII. Recife, Arquivo Público Estadual, 1958, pp. 103 a 107 e 558. 
ferro ${ }^{83}$.

Além destas estradas, o Estado Imperial começou a constru. ir o Prolongamento da Recifé-São Francisco Railway, (depois denominada Estrada de Ferro Sul de Pernambuco) a partir de Palmares, por volta de $1877 / 79$ utilizando-se de mão de obra de flagelados e retirantes. Também foi o caso da EF Caruaru, estatal. Mesmo a empresa inglesa The Great Western, em Pernambuco usou mão de obra de retirantes em sua construção.

A Estrada de Ferro Baturité, contratada em 1870, como em. presa privada, tivera iniciadas suas obras em $1872 / 75$, parou com a seca de 1877. Depois de pronta, esta ferrovia atenderia ao universo de 120 mil pessoas. O governo Imperial encampou a estrada, em 1878, cobrindo as 3.101 ações, porque achava que assim daria trabalho às populaçôes e evitaria que elas chegassem à capital. Só em 1880 é que foi aberto o trecho de Pacatuba a Canoa e em 188/21 o ramal de Baturité. Na seca de 1888, o governo Imperial resolveu construir mais $47 \mathrm{~km}$ em direção a Quixadá. Por volta de 1878, a EF Camocim-Sobral tinha cerca de 1000 homens trabalhando em suas obras. Esta ferrovia atenderia a cerca de $36 \mathrm{mil}$ pessoas ${ }^{\text {s4 }}$.

Em 1889, o engenheiro Chrockatt de Sá, lialvez por influência da seca do ano anterior, já que ele cita uma cronologia de secas, sugere em livro a construção de uma ferrovia de Macau (RN) ao Rio São Francisco. Com estia estrada, diz ele, seriam servidas 160 mil no Rio Grande do Norte, 171 mil na Pará́ba, e 75 mil em Pernambucos.

Mesmo com as ferrovias instaladas na área canavieira, sua utilidade, na Paraíba, se revelou na sèca de 1890. A ferrovia inglesa The Conde D'Eu transportou gêneros que o Governo esta-

${ }^{83}$ SANTANA, op. cit. pp.171 a 174; CAMLO, op. cit. p.47.

${ }^{84}$ BPP, 1878, LXXIII. Brazil. Ceará. Repont by Vice-Consul Studart on the Trade and Commerce of Ceará for the year 1878, p.477; CASTRO CARREIRA, Liberato de. História Financeira e Orçamentária do Império no Brasil, pp.782/3; FERREIRA, Benedito Genésio, op. cit. pp.34/5.

${ }^{85} \mathrm{SÁ}$, Chrockatt de. A Estrada de Ferro Macau ao São Francisco, pạssim. 
dual comprara, além de receber 4 contos e 644 mil-réis para dar passes de graça àqueles retirantes que quisessem retornar ao interior. Com a seca asssolando a área da pequena produção, 500 sacos de farinha foram importados do Maranhão e 4.200 sacas de farinha foram comprados no comércio local, além de 2.492 sacos de feijão (semente) e 1.619 de milho ${ }^{86}$ (ver Tabela no apêndice).

Outras ferrovias tiveram suas construções incentivadas por volta daquele ano, mesmo que fossem de capitais privados como as inglesas The Conde D'Eu Railway, na Paraíba, The Natal-Nova Cruz no. Rio Grande do Norte e The Alagoas Railway Company em Alagoas. Pernambuco ainda veria a construção, naquele período da Great Western Railway Company. Por aí se vê que a seca provocou grande impacto social, a ponto de o Estado ter de intervir com paliativos como construção ferroviária, algumas delas completamente inoperantes, como a Paulo Afonso.

Mas a importância da ferrovia não deve ser medida só pelo transporte de cargas e de passageiros. Falta ainda uma pesquisa sobre como o Estado usou este meio de transporte para levar água potável para as populações afetadas. Encontramos apenas um exemplo, como o transporte de água em vagōes para cidades atingidas pela seca ou por levas de retirantes, na seca de 1891, quando a Estrada de Ferro Caruaru, estatal, subiu a Serra das Russas, levando cinco carros tanques com $50 \mathrm{~m}^{3}$ de água, que foram carregados em Vitória de Santo Antão ${ }^{87}$.

\section{SECA E TRANSPORTE}

As secas nunca atingiram a zona açucareira, senão como estiagem, o que já era um prejuízo para os latifundiáríos. A zona da mata canavieira, no século XIX tem uma dimensão de aproximadamente 10 a 18 léguas (60 a $110 \mathrm{~km}$ ), segundo o contemporâ-

${ }^{86}$ Oficios do Governador do Estado da Paraíba, Venâncio Neiva, à Comissão do Socorros Públicos. Caixa 9. Arquivo Público da Paraíba.

${ }^{87}$ Códice Estrada de Ferro (EF) 28 , Oficio do Engenteiro da ferrovia ao Presidente da Província (de Pemambuco), 14/3/189l. 
neo e socialista saint-simoniano, Antônio Pedro de Figueiredo em Pernambuco. E neste trecho que se situam as ferrovias inglesas, partindo do porto de cada capital provinciana. Até esta fronteira chega o grande exército de tropeiros varando as veredas dos sertão, onde não chegam os trilhos. Segundo técnicos da ferrovia Re. cife-São Francisco, de Pernambuco, durante uma seca ("a dry season") se empregam cerca de 20 mil cavalos e $10 \mathrm{mil}$ homens no transporte de mercadorias ${ }^{88}$.

TRANSPORTE DE GENEROS NA RSF (EM MILHARES DE TONELADAS)

\begin{tabular}{c|r|r|r|r}
\hline Anos & Açucar & \multicolumn{1}{|c|}{$\%$} & Algodao & $\%$ \\
\hline 1876 & 42.4 & - & 0.8 & - \\
1877 & 57.1 & 36 & 1.1 & 37 \\
1878 & 54.9 & 31 & 0.9 & 13 \\
1879 & 52.6 & 26 & 0.5 & -37 \\
1880 & 75.9 & 81 & 0.7 & -13 \\
\hline
\end{tabular}

FONTES: Códices Estrada de Ferro (EF) 14, 15 e 19. Vários relatóríos e balanicetes, de 1876 a 1880; Relatórios do Ministério da Agricultura, diversos relatorios para o perlodo.

Com a seca de 1877 , o transporte da RSF, entre 1877 e 1880 , teve uma queda no transporte de algodão em torno de $37 \%$.

A calamidade de $1877 / 79$ terminou por render lucros às ferrovias privadas pois o governo as contratou para carregar gêneros de primeira necessidade para cidades fronteiriças à área da seca, de onde seriam levados em lombos de burros para as áreas devastadas.

Lm termos de transporte de flagelados, a cidade de Palmares, ponta de trilhos, a época, da RSF, recebeu cerca de 20.000 pessoas, enquanto 60.000 chegaram ao Recife. O governo atacou as obras do prolongamento da RSF com cerca de 3.000 flagelados,

88 FIGUERREDO, Antônio Pedro de. Op. cit. p.635; Códice Estradas de Ferro, (EF) 4. Prospecto da Recife São-Francisco Railway (RSF), impresso.

${ }^{89}$ Ministério da Fazenda. Relatótios e Anexos para os anos de 1877 a 1880 ; Proposta o Relatório do Ministório da Fazenda (1882/3); Idem, Relatório de 1884; Idem, de 1886/6; EF 15 , vários oficios e balancetes da RSF, de 1876 a 1880 . 
mas riem pode empregar todos. $O$ restante ficou andando pelas propriedades, pedindo comida, assaltando fazendas e engenhos e pessoas avulsas. Em dois meses, em 1877, 232 pessoas morreram na cidade de Quipapá (PE), ondè a ferrovia estatal tinha um escritório. $O$ custo de vida cresceu demais, principalmente no caso da farinha de mandioca que alcancou $1.000 \%$ de aumento ${ }^{90}$.

No tocante ainda a transporte de passageiros, o movimento da RSF não toi alterado pela seca, nem mesmo quanto à terceira classe, quando se relaciona o tráfego com o número de flagelados. Talvez este contigente não fizesse parte da contabilidade da ferrovia.

\begin{tabular}{l|r|r|r}
\hline Anos & \multicolumn{1}{c|}{$\boldsymbol{1}^{\circ}$ Classe } & \multicolumn{1}{c}{$\mathbf{2}^{\circ}$ Classe } & \multicolumn{1}{c}{ 3 $^{0}$ Classe } \\
\hline 1876 & 22.445 & 18.791 & 116.638 \\
1877 & 26.678 & 21.954 & 139.219 \\
1878 & 22.917 & 22.413 & 139.219 \\
1879 & 23.317 & 21.066 & 135.124 \\
1880 & 21.495 & 22.035 & 137.122 \\
\hline
\end{tabular}

Fonte: Relatório do Ministério da Agricultura, 1883, pp. 252/260.

$\mathrm{O}$ ano de 1876 não é bem elucidativo, porque faz parte de uma queda. Em 1873 foram $160 \mathrm{mil}$ os passageiros da terceira classe; caiu este tráfego, no ano seguinte para 145 mil e em 1875 foi de $135 \mathrm{mil}$.

\section{SECA É MÁo de OBRA}

A seca sempre atingiu as regiōes fisiográficas do Agreste e Sertão, o que levava grande número de camponeses a abandonar

${ }^{90}$ Relatórios de Presidentes da Província (de Penuambuco) (R.93-A) "Contratos 1878"; EF 15. Oficios de Mr. Wells Hood ao Presidente da Província, em 15 de julbo de 1878; idem, Balancete da RSF, em 9 de Outubro de 1878; EF 18. Oficio de H.E. Weaver, Chefe interino da EF Sul de Pernambuco ao Presidente da Provincia, em 3 de junho de 1878; CAMLO, Josemir. A Seca de 1877 a a Mão de Obra na Zona da Mata em Pemambuco. Recife, 1978; MALA, Nayala de Souza Ferreira. Açúcar e Transição para o Tłabalho Livre um Pemambuco. 
seus terrenos arrendados ou aforados e irem a pé para a zona canavieira ou para o litoral. Esta leva de migrantes tornava-se mão de obra barata, senão gratuita, para o. trabalho nos engenhos, como frente de trabalho, administrado pelo Estado. As ferrovias privadas também se utilizavam desta mão de obra flutuante, pagando preços abaixo do mercado que, segundo seus argumentos, serviria para compensar a queda do transporte de algodão e de outros gêneros do interiur para o porto.

A forma encontrada pelo Fstado Imperial foi a de fundar colônias em terras de engenhos canavieiros na zona da mata. $\mathrm{Ou}$ tra parte desta mão de obra ló utilizada pelo próprio Estado em obras públicas.

Em Alagoas, criou-se a Colônia São Francisco, onde antes eram terras dos índios de Porto Real do Colégio, chegando a 12.000 retirantes. Em 1878, já havia 128 retirantes trabalhando no engenho Três Bocas, número que chegou a 395. Todos deveriam trabalhar 3 dias para os proprietários e 3 para si. A Colônia São Francisco ia ser fundada em terras da ex-Colônia Militar de Leopoldina, mas o governo desistiu da idéia, porque nem estrada de rodagem havia para aquelas bandas".

No Rio Grande do Norte, fundaram a colônia. Bom Jesus dos Navegantes com 3.600 pessuas e outra, a Vera Cruz com 600 pessoas $^{92}$.

Em Pernambuco, o governo tentou alocar os flagelados em colônias de camponeses ou explorar sua mão de obra em obras públicas, como reparos de estradas, o que no fundo gerava um beneficio para a ferrovia RSF, já que os caminhos melhorados pelos flagelados, serviam para escoar os produtos para as estaçōes ferroviárias. Tal era a situaçâo de uma colônia situada perto da RSF, com cerca de 5.000 pessoas, que estravam engajados em abrir estradas. Até a política de incentivo ao plantio do café foi afetada, pois a seca havia atingido os 2 milhões de pés de café plantados em Bonito. Nguns desses migrantes terminavam por arranjar

\footnotetext{
91 SANTANA, op. cit. pp. 171 a 174; CAMEQ, op. cit.p.47.

${ }^{92}$ CÄMARA CASCUDO, Luís da. op.cit. pp. 184/5.
} 
emprego sazonal nos engenhos. Uma das obras públicas, como a rodagem ligando Palmares a Bonito, empregou cerca de 1.200 pessoas da seca à diária de 53 mil-réis ${ }^{93}$.

Os flagelados foram alojados em 14 engenhos, onde receberiam dos proprietários cerca de 400 gramas de farinha de mandioca, 200 gramas de carne seca e $125 \mathrm{gr}$. de feijão e uma muda de roupa de algodão para os homens e um vestido de chita para as mulheres. Metade da alimentação seria dada durante três meses até que estivessem produzindo alguma lavoura em terras dos engenhos ${ }^{94}$.

\begin{tabular}{l|c}
\hline \multicolumn{1}{c|}{ Engenhos } & Trabalhadores \\
\hline Panguá & 650 \\
São Jogé & 253 \\
Colégio & 220 \\
Mundo Novo & 131 \\
Condado & 136 \\
Utinga & 116 \\
\hline Fonte: Relatórios de Presidentes de Provincta, 1879.
\end{tabular}

O salário diário nominal, por volta de 1876 , estava em $1 \$ 000$ (um mil-réis/US\$ 55) enquanto o real estrava em 581 réis $^{95}$. Mesmo assim, a discrepância era grande em relaçāo aos salários pagos pelo governo aos flagelados.

93 Railway Times (London) October 12, 1878, p.865.

94 CAMLLO, op. cit. p.46.

${ }^{95}$ EISENBERG, Peter. Modenuzação sem Mudanças, pp, $208 / 210$ e 268. 
SECA E SALÁRIOS RURAIS

(DIÁRIAS/MIL-RÉIS) (1879)

\begin{tabular}{l|c|c|c}
\hline \multicolumn{1}{c|}{ Profissáo } & Quantidade & Salarios & Total \\
\hline Fiscal de obras & 5 & 72 & 360 \\
Chefe de obras & 22 & 65 & 1.440 \\
Administrador-armazém & 1 & 60 & 60 \\
Asgistente-armazém & 1 & 45 & 45 \\
Enfermeiro & 1 & 60 & 60 \\
Cozinheiro & 1 & 45 & 45 \\
Mestre-Pedreiros & 2 & 60 & 120 \\
Pedreiros & 8 & 12 & 96 \\
Mestres Oleiros & 2 & 45 & 90 \\
\hline \multicolumn{1}{c|}{ Total } & 44 & 50 (média) & 2.316 (média) \\
\hline
\end{tabular}

FONTE: Relatórios de Presidentes de Provincla (RPP), vários relatórios para o ano 1879; RPP,

"Contratos, 1878"; CAMILO, Josemir. A Seca de 1877, op. clt. p 48.

A maior parte deste exército de miseráveis trabalhava somente por roupas e comida, como era de praxe os proprietários rurais fazerem, mesmo trabalhando aqueles nos engenhos de açúcar. Em geral, as diárias quando eram pagas, estavam abaixo das pagas antes de a RSF se instalar, na década de 1850.

Na Paraiba, fundam uma colónia na propriedade de Nossa Senhora da Guia, dos padres carmelitas, perto do litoral e mais 2 na capital e $3 \mathrm{em}$ Mamanguape. De fato, foram 30 colônias fundadas, num total de 1.868 famílias, compostas estas por 8.664 pessoas, o que dava cerca de 62 famílias ou 288 pessoas, por colônia. Não havia remuneração, trabalhava-se por uma muda de roupa, alimentação e ajuda por 8 meses. Em abril de 1880 havia 31 colônias, todas em terrenos de particulares, com cerca de 12 mil retirantes. Parte dos colonos foi dispensada por se recusar a trabalhar ${ }^{96}$. 
COLÔNIAS DE FLAGELADOS NA PARAÍBA

\begin{tabular}{|c|c|c|}
\hline Nicleos & Pessoas & Familios \\
\hline Abiay & $41 \overline{4}$ & 1.11 \\
\hline Amparo & 332 & 80 \\
\hline Barra do Gramame & 100 & 32 \\
\hline Camocim & 187 & 56 \\
\hline Cana-Brava & 97 & 21 \\
\hline Cosme e Damião & 233 & 50 \\
\hline Espírito Santo & 436 & 75 \\
\hline Gramame & 58 & 14 \\
\hline Guarita & 232 & 46 \\
\hline Tha & 186 & 24 \\
\hline Jagarafa & 521 & 98 \\
\hline Leite Mirim I & 133 & 42 \\
\hline Leite Mirim II & 133 & 29 \\
\hline Marcos João & 134 & 30 \\
\hline Mata Limpa & 648 & 137 \\
\hline Miriri do Lagamar & 76 & 14 \\
\hline Miriri do Meio & 267 & 49 \\
\hline Musguré & 1677 & 366 \\
\hline Nascença do Una & 275 & 58 \\
\hline Nova Libéria & 305 & 69 \\
\hline Pan Brasil & 329 & 86 \\
\hline Ponte do Gramame & 127 & 27 \\
\hline Puxi de Baixo & 405 & 78 \\
\hline Ribeira & 86 & 20 \\
\hline Rio do Meio I & 191 & 20 \\
\hline Rio do Meio II & 93 & 22 \\
\hline S. Izabel & 206 & 45 \\
\hline Santana do Gargau & 273 & 45 \\
\hline Tauá de S. André & 118 & 30 \\
\hline Tauá do Tibiri & 392 & 94 \\
\hline TOTAL & 8.664 & 1.868 \\
\hline
\end{tabular}

\section{CONCLUSĀO}

As ferrovias construídas no século XIX, antes e depois da seca de 1877, poderiam ter contribuído muito para mitigar a calamidade entāo reinante, se tivessem sido abertas em direção ao 
sertão algodoeiro e agro-pastoril. Só na década de 1880 é que, timidamente, as ferrovias estatais chegaram a áreas algodoeira (Garanhuns, Caruaru, Limoeiro) e só no século XX é que uma ferrovia inglesa subiu a Serra da Borborema, fazendo ponta de trilho numa cidade eminentemente algodoeira, Campina Grande, na $\mathrm{Pa}$ raíba, em 1907.

Desta forma, a área mais vulnerável à seca, o sertão - hoje delimitado como "polígono das secas" - ficou sem ferrovias durante a segunda metade do século XIX, com exceção do contorno da Cachoeira de Paulo Afonso, que ganhara na década de 1880, uma ferrovia, mas que, infelizmente foi mal projetada, tornandose obsoleta e onerosa ao Estado

A tentativa de o Governo construir ferrovias no Nordeste, durante a seca de 1877, funcionou como anteparo da migração campo-cidade, não só como tentativa de reter o pessoal em sua região, mas, principalmente, a de devolver mais rápido esta população flagelada a suas terras. As tentativas de colonizar terras particulares com mão de obra de retirantes, foi não só um paliativo, mas serviu de mão de obra barata para os plantadores de cana, beneficiou serviços de infra-estrutura em torno das ferrovias inglesas e, depois, da seca, estes trabalhadores foram mandados de volta a suas terras, sem nenhum ganho, nem a posse da terra colonizada. Toda esta política se mostrou paliativa. O fenômeno voltaria a se repetír no século XX, mas já aí, o Estado se utilizaria das rodovias e de uma instituiçāo criada para maquiar os efeitos da seca, o IFOCS (Inspetoria Federal de Obras Contra a Seca 1909/1945) depois DNOCS (Departamento Nacional de Obras Contra a Seca) até 1990, quando foj extinto. 


\section{APÊNDICE}

VÍtIMAS DA SECA DE $1877 / 9$ (EM MILHARES)

\begin{tabular}{l|c|c|c}
\hline \multicolumn{1}{c|}{ Provincia } & $\begin{array}{c}\text { Populaçá } \\
\text { Estimada }\end{array}$ & $\begin{array}{c}\text { Populacáo } \\
\text { Atingida }\end{array}$ & $\%$ \\
\hline Piaú & 202 & - & \\
Ceará & 800 & 720 & 90 \\
Rio Grande do Norte & 234 & 117 & 50 \\
Paraíba & 362 & $60^{*}$ & $16^{* *}$ \\
Pernambuco & 841 & 200 & 24 \\
Alagoas & 348 & 50 & 14 \\
Sergipe & 161 & 30 & 19 \\
Babia & 1.283 & 500 & 39 \\
\hline TOTAL & 4.231 & 1.667 & 39 \\
\hline
\end{tabular}

Fonte: Dados abreviados de Rebouças, André. A Seca nas Provincias do Norte. Socorros Públicos. Rlo de Janeiro, 1877, pp.32/4. Os daclos sáo estimativas daquele autor; (*) Os dados para a Paralba sáo do Cônsul inglês. Ver BPP LXXV, 1878. Report by Consul Walker on the Famine In the Northern Provinces of Braziz. 1878; ("*) Há defasagem, pois os dactos sao de fontes diferentes.

TABELA

CONSTRUÇÃo FERROVIÁRIA NA NORDESTE (1870s)

\begin{tabular}{l|c|c|c|c}
\hline \multicolumn{1}{c|}{ Ferrovia } & Concessáo & Consirução & Aberta & $\begin{array}{c}\text { Extensão } \\
(\text { Km })\end{array}$ \\
\hline Estatais & 1873 & 1878 & 1878 & 110 \\
Baturité & 1871 & 1876 & 1882 & 146 \\
Sul de PE. & 1871 & 1876 & 1881 & 322 \\
Alagoinhas & 1878 & 1878 & 1885 & 133 \\
Sobral & 1878 & 1878 & 1882 & 126 \\
Caruaru & 1878 & 1878 & 1883 & 117 \\
P. Afonso & & & & \\
Inglesas & 1875 & 1880 & 1883 & 166 \\
Conde D'Eu & 1875 & 1879 & 1881 & 180 \\
GWBR & 1875 & 1880 & 1881 & 120 \\
NNC & 1881 & 1882 & - & 120 \\
Alagoas Ry & & &
\end{tabular}


TRANSPORTE DE GÊNEROS NA SECA DE 1890

\begin{tabular}{l|c|c|c|c}
\hline \multicolumn{1}{c|}{ Localidades } & Milho & Feijäo & Farinha & Arroz \\
\hline Santa Rita & 50 & 50 & 60 & - \\
Sapé & 20 & 20 & 30 & - \\
Mulungu & 1.000 & - & - & 10 \\
Guarabira & 680 & 500 & - & - \\
Bananeiras & 100 & 50 & - & - \\
Araruna & - & - & 80 & - \\
Pilar & - & - & 60 & - \\
Ingá & 10 & 10 & 60 & - \\
Mogeiro & 30 & - & 30 & - \\
\multicolumn{1}{c}{ Cachoeira de Ce- } & 20 & 20 & 40 & \\
bolas & & & & \\
\hline
\end{tabular}

FONTE: Offclos do Govemador do Estado Venãncio Neiva a Comissão de Socorros Públicos. Caixa 9. Afquivo Público da Paraiba.

\section{CRONOLOGIA DAS SECAS NO SÉCULO XIX}

1803/4 Paraíba.

1809 - sem local determinado

1816/7 parcial, pouca duração, sem local definido

1824/5 Paraíba e Pernambuco

$1826 / 7$ secas parciais

1830 falta de chuvas na Paraíba

1835/7 sem indicacão de lugares

1841/6 Paraíba e Pernambuco.

1851 e 1853 repiquetes - inverno falho

1860 repiquetes

$1865 / 66$ idem

1867/70 - principalmente no Ceará

$1869 / 70$ - repiquete

1870/72 - Alagoas e Pernambuco 
$1877 / 79$ - todo o Nordeste

1888/9 - principalmente no Ceará

1889 repiquetes

$1891 / 2$ repiquetes

1895 seca

1896 repiquetes

1898 - Ceará

1889 seca no Rio Grande do Norte e Paraíba

1900/1 - principalmente no Ceará

\section{Bibliografia}

ALMEIDA, Jogé Américo de. Paraíba e seus Problemas. (3ª edição) João Pegsoa, A União, 1980.

BEAUREPAIRE-ROHAN, Henrique. Considerações Acerca dos Melhoramentos de que em Relação às Secas sáo Susceptíveig Algumas Províncias do Norte do Brasil. $2^{a}$ ed. Rio de Janeiro, Typographia do Globo, 1877.

CASCUDO, Luís da Câmara. História do Rio Grande do Norte. Rio de Janeiro. Instituto Nacional do Livro, 1955.

CASTRO CARREIRA. Liberato de. História Financeira e Orçamentária do Império no Brasil. Rio de Janeiro, Fundação Casa de Rui Barbosa, 1980. (2 vols.)

CONRAD, Robert. Os Ítimos Anos da Escravatura no Brasil. Rio de Janeiro, Civilização Brasileira,/Ministério da Educação e Cultura, 1975 .

COSTA PORTO, (José da). O Drama Secular. Revista do Museu do Açucar, Recife, V.3, 1969, pp.7.12.

CUNHA, Euclides da. A Margem da História. Lisboa, Lello Brasileira, 1967.

EISENBERG, Peter. Modernização sem Mudanças. A Indústria Açucareira em Pernambuco: 1840/1910). Rio de Janeiro, Paz e Terra/UNICAMP, 1977.

FERREIRA. Benedito Genégio. A Estrada de Ferro de Baturité: 18701930. Fortaleza. Universidade Federal do Cearal Styllus, 1989.

FERREIRA. Lúcia de Fátima Guerra. A Seca de 1877 na Paraíba. In: Revista de Ciências Humanas, Ano 2, No4, UFPb. João Pessoa, outubro/dezembro, 1980; 
FIGUEIREDO, Antônio Pedro de. O Progresso, Revista Sacial Litteraria e Scientifica, Recife, Imprensa Oficial, 1950 (2a edição).

GARDNER, George. "Travels in the Interior of Brazil, prineipally throug the Northern Provinces and the Gold and Diamond Districts during the year's 1836-1841". New York, 1970.

GUERRA, Phelippe e GUERRA, Theóphilo. Seccas contra Secca. Natal, 1974 (Coleção Mogsoroense, 29)

MAIA, Nayala de Souza Ferreira. Açúcar e Transiçăo para o Trabalho Livre em Pernambuco, 1874/1904. Recife, Univergidade Católica de Pernambuco, 1985.

MARIZ, Celso. Ibiapina, um Apóstolo do Nordeste. João Pessoa, Uñiversidade Federal da Paraíba ( $2^{\text {a }}$ edição) 1980.

MELO, Josemir Camilo de. Ceará: Aboliçăo Precoce ou Crige Econômica? Cadernos NUDOC, UFCE, (Namero Especial) Fortaleza, 1988, pp. $33 / 39$

Ingleses na Parába: The Conde D'Eu Railway, Grão, Ano I, N4, Universidade Federal da Paraíba, Campina Grande, 1985, pp.81-97.

The Effects of British Investments on Railway. (Inédito)

(Melo) CAMILO (de), Jogemir. A Seca de 1877 e a Máo de Obra na Zona da Mata em Pernambuco. Revista de História Municipal, Centro de Estudos de Historia Municipal, Recife, 1991, pp . 43-50

PEREIRA DA COSTA, F.A. Anais Pernambucanos, Vol VII. Recife, Arquivo Público Estadual de Pernambuco, 1950.

PINHEIRO, Francisco José. O Homem Livre/Pobre e a Organização das Relações de Trabalho no Ceará (1850-1880) In Revista de Ciências Sociais, Vol.20/21, No 1/2, UFCE, Fortaleza. $1989 / 90$.

PINTO, Irine ferreira. Datas e Notas para a Histónia da Paraíba. João Pessoa, Editora Universitária/TFPB, 1977 ( $2^{\circ} \mathrm{Vol}$ )

REBOUÇAS, André. A Seca na s Províncias do Norte. Socorros Públicos. Rio, 1877.

SÁ, Chrockatt de. A Estrada de Ferro Macau ao Sao Francisco. Rio de Janeiro, 1889.

SANTANA, Moacir Medeiros de. Con tribuiçôes à História do Açucar em Alagoas. Recife, Museu do Açucar, 1970.

SILVA, Alípio Pereira da. Considerações Gerais sobre as Provincias do Ceará e Rio Grande do Norte, . p.4

SLVA, Clodomiro Pereira da. Política e Legislação de Estradas de Ferro: São Paulo, 1904.

TAKEYA, Denise. IIm Outro Nordeste: O Algodzo na Economia do Rio grande do Norte (1880-1915). Fortaleza, Banco do Nordeste 
do Brasil, 1985.

\section{Documentaçăo}

Arquivo do Itamaraty. Diversos ofícios de autoridades brasileiras trocados com dirigentes de ferrovias londrinas.

Arquivo Estadual Jordåo Emerenciano, Recife. Diversos códices manuscritos. Estrada de Ferro. oficios e balancetes da Recife-Sao Franciseo e relatórios dos engenheiros fiscais de diversas ferrovias pernambucanas).

Arquivo Páblico da Paraíba, Vários ofícios do Presidente do Estado Venâncio Neiva para a Comigsăo de Socorros Públicos, Paraíba, 1890, ex.9

Ministério da Fazenda. Relatórios e Anexos para os anos de 1877 a 1880; Proposta e

Instituto Histórico e Geográfico Brasileiro. Notas do Conde D'Eu escritas durante viagem pelas Provincias do Norte do Brasil (...) 1889.

Núcleo de Documentação e Informaçåo Histórica Regional (NDIHR) UFPB. Relatórios de Presidentes de Província da Paraíba e Rio Grande do Norte.

Relatório do Miniatério da Fazenda (1882/3); Idem, Report for 1884; Idem, para 1886/6;

Public Record Office (Londres). Sessão Foreign Office. British Parliamentary Paper. Relatórios diplomáticos da Legaçăo Britanica no Brasil.

Relatórios de Pregidentes de Província (Pernambuco) (R.93-A). "Contratos 1878";

The Railway Times 